Original Research

\title{
Feeding Time and Agonistic Behavior in Horses: Influence of Distance, Proportion, and Height of Troughs
}

\author{
Marina P.F. Luz ${ }^{a}$, Caroline M. Maia ${ }^{b, *}$, José Carlos F. Pantoja ${ }^{a}$, Marcos Chiquitelli Neto ${ }^{c}$, \\ José Nicolau P. Puoli Filho ${ }^{\text {a }}$ \\ a University of Veterinary Medicine and Animal Husbandry (FMVZ), Universidade Estadual Paulista "Júlio de Mesquita Filho", Botucatu, São Paulo, Brazil \\ b Laboratory of Animal Physiology and Behaviour, Department of Physiology, IBB, Universidade Estadual Paulista "Júlio de Mesquita Filho", Botucatu, \\ São Paulo, Brazil \\ ${ }^{\mathrm{c}}$ University of Veterinary Medicine and Animal Husbandry (FMVZ), Universidade Estadual Paulista “Júlio de Mesquita Filho", Ilha Solteira, São Paulo, Brazil
}

\section{A R T I C L E I N F O}

\section{Article history:}

Received 9 May 2015

Received in revised form 14 July 2015

Accepted 4 August 2015

Available online 10 August 2015

\section{Keywords:}

Horse

Feeding

Trough

Agonistic behavior

Pinned back ears

\begin{abstract}
A B S T R A C T
Horses express social-based organizations when grouped and also show conflicts over resources, which can progress to agonistic interactions. The domestication led horses to be fed in confinement, which may have had increased the competition for food. We tested whether the distance, height of positioning, and proportion of feeding troughs affect the agonistic behavior in horses, and whether such effects are influenced by the social stability. We simultaneously varied these three factors at two levels (eight treatments). The group of horses $(n=8)$ was subjected to all treatments in a primary phase (no previous experience of feeding ration together) and in a secondary phase (social relationships better established by the agonistic interactions in the primary phase). In each treatment, we recorded agonistic behaviors during 30 minutes while horses were feeding. A distance of $10 \mathrm{~m}$ and a height of $0.71 \mathrm{~m}$ of the troughs reduced kick behavior, regardless of the phases evaluated. For agonistic signaling pinned back ears behavior, initially, a far distance $(10 \mathrm{~m})$, low positioning ( $0 \mathrm{~m}$ of height), and a greater proportion of feeding troughs (1.5 per horse) reduced this behavior. However, in the secondary phase, the effect of distance was consistent, but the effects of height positioning and proportion were opposite. Moreover, pinned back ears was the most frequent agonistic behavior. We conclude that the effect of height and proportion of troughs on agonistic behaviors of horses may depend of the social stability, whereas a far distance between troughs reduces the most frequent agonistic behavior, regardless of such social homeostasis.
\end{abstract}

(c) 2015 Elsevier Inc. All rights reserved.

\section{Introduction}

The competition for environmental resources is a strategy that can involve disputes. The agonistic interaction depends on the motivation for the dispute and is balanced by the value of resources being disputed and the risk of injury [1]. The establishment of a prior social homeostasis can influence disputes, and the dominant

\footnotetext{
* Corresponding author at: Caroline M. Maia, Department of Physiology, IBB, Universidade Estadual Paulista “Júlio de Mesquita Filho", Distrito de Rubião Júnior, S/N. CEP: 18618-970 Botucatu, São Paulo, Brazil.

E-mail address: carolmm_luzi@hotmail.com (C.M. Maia).
}

animal usually wins [2]. When the social stability is not clear yet and the individuals are similar in body size, individuals tend to solve disputes over environmental resources in an unpredictable way, which is expected to vary according to the environmental context [3]. Moreover, taking into account that food usually is considered as the most valuable resource, being used as a parameter to compare with the value of other resources in motivation tests [4-6], the agonistic interactions may be increased in situations of food competition. Such interactions may result in increased stress, lower growth, and even lower survival. 
Horses (Equus caballus) express their organization as a kind of social homeostasis in a way that the cohesion of the group is determined and affected by the type and quality of relationships between individuals. The social stability is usually established by the postconflict friendly reunions [7] as a response for the agonistic interactions between horses generated by the competition for a given resource [8]. The social stability in horses is primarily threatened when there is a limited space for feeding, which may force the horses to enter into the "flight zone" (a certain space around each horse where there is a second order of dominance that should not be invaded [9]) of the others. In this context, the domestication process and subsequent confinement and restriction of space for feeding may lead equines to increase agonistic and competitive behaviors.

According to Meyer [10], the feeding troughs for horses should be large enough, so that food can be distributed in a thin layer, to prevent excessively fast ingestion of food. Moreover, the same author recommends that the trough edge is in contact with the animal, being positioned in a way that during feeding there is no excessive angulation of the neck and head of the animal. However, such characteristics were based on individual horses only, disregarding the social relationships which are naturally a part of the behavioral repertoire of this species. If horses express a social stability that can be threatened by restrictions of space when feeding in groups, what would be the appropriate distance between troughs or proportion of them per individual to avoid excessive agonistic interactions? This aspect has been neglected and is emphasized, considering that horses are usually fed in groups, not individually.

Moreover, there is still no consensus on the most appropriate height positioning of the troughs to provide food to the horses. Some owners claim that the trough must be positioned above the height of the horse's chest, with a minimum depth of $20 \mathrm{~cm}$ [11]. This positioning would be low enough to allow the correct angulation of the horse's neck. In contrast, Wheeler [12] argued that the positioning of the trough at a high level above the ground is not natural for horses, and Merico [11] suggested the use of troughs at ground level should allow greater elongation of the neck and back of the animal. However, such considerations were again based on individual feeding of horses, disregarding the possible influences on agonistic behaviors among individuals when feeding in groups. Could horses feeding at lower troughs, as the natural grazing level, be more exposed and vulnerable to other group members, which would lead to increased agonistic behaviors? Moreover, could the social stability influence such effect?

In this context, here, we evaluated whether the distance, the proportion, and the height positioning of feeding troughs affect agonistic behaviors in horses when they are feeding together, and whether such effects are influenced by the social stability. As an hypothesis, we proposed that agonistic behaviors would be significantly less frequent when horses are feeding together in troughs separated by a far distance, greater proportion, or at average height of horse breast rather than in troughs arranged close to each other, being in a proportion of just one per individual or positioned at the ground level.

\section{Materials and Methods}

\subsection{Animals and Housing Condition}

We tested eight healthy gelding male horses of unknown bloodline, that were aged about 10 to 13 years (mean $=12.5$ ) and 340 to $380 \mathrm{~kg}$ in weight (mean = $360 \mathrm{~kg}$ ). They remained exclusively on pasture, and the commercial ration was offered only sporadically (animals used for farm work or during drought periods). Before we started the experiment, all the animals already knew each other, but the social relationships were not constant as they had been separated in some periods. These horses had no previous experience of feeding on commercial ration together.

\subsection{Familiarization Phase}

First, the animals were subjected to the experimental conditions for eight days, in a process of familiarization. The two height levels of troughs later used for the treatments were randomly alternated between days. The proportion and distance between troughs were maintained at levels in between the ones later used in the treatments. Thus, the animals were preadapted to the experimental conditions.

\subsection{Experimental Design}

\subsubsection{General Description}

We simultaneously varied three independent factors: the distance between the feeding troughs, the proportion of troughs per individual, and the positioning height of such troughs, being that each of these three factors were varied in only two levels (full factorial $2 \times 2 \times 2$ experiment), thus composing eight treatments. The horse group was submitted to all treatments (one treatment per day), which were applied in a randomized order over the eight consecutive days of experimentation by raffling the treatments. As soon as any individual horse started to feed in the troughs in each treatment, we filmed the horses for a period of 30 minutes by a video camera (all the horses basically started to feed together). Registrations of behavioral frequencies indicative of agonistic interactions of each horse were made from videos by the same observer via a focal sampling technique. Every day in the morning, after the trial, the tested horses $(n=8)$ had free access to pasture. These procedures were repeated for the same group of horses in a primary phase (test 1 ), when there was no previous experience of horses feeding together on ration, and in a secondary phase (test 2 ; immediately after test 1 ), when the social homeostasis was probably better established.

\subsubsection{Test Facilities}

The experiment was conducted in a closed round pen $\left(1,221.7 \mathrm{~m}^{2}\right)$ located in the Equine Production of Teaching, Research and Extension Farm (FEPE), University of Veterinary Medicine and Animal Husbandry (FMVZ), UNESP, Botucatu, São Paulo, Brazil. 


\subsubsection{Procedure}

Individual troughs used in the treatments were all similar to each other, being movable and made of metal $(35 \times 30 \times 31.5 \mathrm{~cm})$. For the treatments which included raised troughs, these were engaged by hooks to bases ( $0.71 \mathrm{~m}$ of height) that were firmly fixed to the ground. During the experimentation, we provided the animals with usual commercial ration, comprising about 10 to $12 \%$ of crude protein and 2 to 3\% of ether extract [13] in such troughs. As the amounts of ration should not exceed $1 \%$ of the animal live weight [13], we calculated the amount available in each trough based on individuals live weight (=2 kg of ration per trough, based on $0.5 \%$ of body weight). The arrangement of the troughs in each treatment was circular, with such troughs being positioned over circumferences drawn on the ground whose origins coincided with the center of the round pen (Fig. 1; ground pen diameter of $39.45 \mathrm{~m}$ ). Given the proportion of troughs per individual, as well as the distance between such troughs specified in each treatment, we calculated the radius of each circumference, which can be expressed by:

$r=d N c / 2 \pi$

In (1), $r$ is the radius of the circle, $d$ is the distance between the troughs, and $N c$ is the total number of troughs.

The two levels of distance between troughs were $1.60 \mathrm{~m}$ (near) and $10 \mathrm{~m}$ (far). These two different distances were selected once the "flight zone" for each horse is about $1.5 \mathrm{~m}$ [14]. Thus, for the treatments with $1.60 \mathrm{~m}$ of distance, the "flight zone" was, at least, almost invaded. For treatments with $10 \mathrm{~m}$ of distance between troughs, we ensure that this individual zone was maintained and that all individuals had their own space to feed. For the proportion of troughs per individual, such levels were set by a factor of 1 (eight troughs for eight horses) and 1.5 (12 troughs for eight horses). Evaluated levels of height positioning of the troughs were $0 \mathrm{~m}$ (low; at ground level) and average height of horse breast $(0.71 \mathrm{~m}$ from the upper edge of the trough to the ground; Supplementary Data).

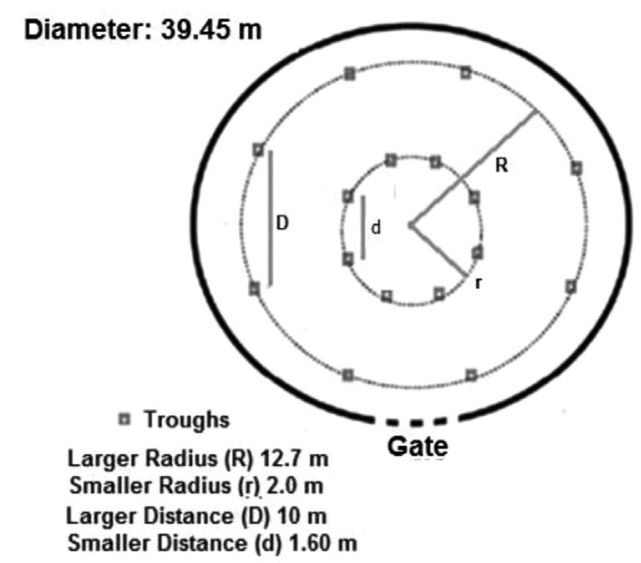

Fig. 1. Schematic representation of the arrangement of troughs in the experimentation area for treatments that included eight troughs per individual (proportion of one) at two levels of distance between such troughs (1.60 and $10 \mathrm{~m})$.

\subsection{Parameter Analyzed}

The recorded agonistic behaviors in each treatment were: bite; kick; rush, and pinned back ears (for clarification, see Table 1). Through the frequencies obtained for such behaviors, we inferred the agonistic interactions of individuals in each treatment per phase.

\subsection{Statistical Analyses}

First, we evaluated whether any of the agonistic behaviors (rush, bite, kick, or pinned back ears) was the most frequent among individuals. These comparisons were made per treatment, phase, and individual with the Goodman proportion test [16]. As this test compares frequencies, there was no need to test the normality and homoscedasticity of the data. For comparisons, we set $\alpha=$ 0.05 .

To evaluate the effects of the factors and the phases (tests) on the agonistic behaviors, we used generalized linear models (Poisson regression, PROC GLIMMIX; SAS Institute, 2011). An interaction term between treatments and phases was included in all models to test the hypothesis that the difference between phases was dependent on treatments (interaction effect). The Tukey test was used to adjust the $P$ values resulting from multiple comparisons. When there was no difference of treatments between the two phases or an interaction effect between treatments and phases, we added the behavioral frequencies across the tested phases and analyzed the effects on such behavior again in the way described previously, but removing the interaction term. For these comparisons, we also set $\alpha=$ 0.05 . We restricted the consideration of significant differences $(P<.05)$ in comparisons between two treatments to those which only one of the factors varied in level.

\subsection{Ethics Statement}

All the procedures agree with the ethical principles in animal experimentation and were approved by the Ethics Committee on the Use of Animals (CEUA) of FMVZ (UNESP, Botucatu, São Paulo, Brazil), protocol number: 147/2012CEUA.

\section{Results}

\subsection{Differences Between Agonistic Behaviors}

The pinned back ears behavior was significantly more frequent than all the other three agonistic behaviors in $91.4 \%$ of the comparisons, and there was no case of any other agonistic behavior which was significantly more frequent than pinned back ears (Goodman proportion test, within multinomial [16], $P<.05$ ).

\subsection{Effects of Proportion, Height, and Distance of the Troughs on Agonistic Behaviors}

There was no effect of the phases (tests) or of the interaction between phases and treatments on rush, bite, and kick behaviors (generalized linear models, $P>.05$; data 
Table 1

Description of the agonistic behaviors of horses recorded during 30 minutes in each treatment per phase, while the animals were feeding on ration.

\begin{tabular}{ll}
\hline Agonistic Behaviors & Description \\
\hline Bite & "Ears laid back, head raised, open mouth, and extension of head and neck toward another horse, attempting to close \\
& teeth on its body" [15] \\
Kick & "Ears laid back and projection of one or both hind limbs toward another horse, attempting to strike it" [15]. \\
"Eush & attempting to close teeth on its body" [15]. \\
Pinned back ears & "Ears laid back and looking at or walking toward another horse" [15]. \\
\hline
\end{tabular}

not shown). Even considering the behavioral data added across the two tested phases, there was no effect on the behaviors of rush and bite (Tables 2 and 3). However, the far distance between troughs $(10 \mathrm{~m})$ and the height positioning of troughs at the high level $(0.71 \mathrm{~m})$ reduced the added behavioral frequencies of kick, the first in two comparisons (see comparisons between treatments five and seven, six and eight; Fig. 2) and the latter in just one comparison (see the comparison between treatments one and five; Fig. 2).

In contrast, there was an effect of interaction between phases and treatments on pinned back ears behavior. In the primary phase (test 1), treatment one (distance: near; height positioning: high; proportion per individual: one) significantly showed the highest frequency of this behavior (Fig. 3A). Furthermore, a greater proportion of troughs per horse (1.5), the far distance between troughs (10 m), and the low positioning of troughs $(0 \mathrm{~m})$ reduced the occurrences of pinned back ears in three, two, and one comparisons, respectively (see comparisons between treatments three and four, five and six, seven and eight; treatments two and four, six and eight; treatments four and eight, respectively; Fig. 3A).

In the secondary phase (test 2 ), the far distance between troughs $(10 \mathrm{~m})$ reduced the frequency of the pinned back ears as in the primary phase, but in four comparisons (see comparisons between treatments one and three, two and four, five and seven, six and eight, Fig. 3B). However, contrary to the primary phase results, a lower proportion of troughs per horse (one) and the disposition of the troughs

Table 2

There was no difference in behavioral frequencies of rush between treatments, independent of the tested phase (generalized linear models, $P>.05 ; \mathrm{n}=8)$.

\begin{tabular}{|c|c|c|c|c|}
\hline \multicolumn{5}{|l|}{ Rush } \\
\hline \multicolumn{3}{|l|}{ Factors } & \multirow[t]{2}{*}{ Treatments } & \multirow{2}{*}{ Mean $\pm S D$} \\
\hline Height $^{\mathrm{a}}$ & Distance $^{b}$ & Proportion & & \\
\hline \multirow[t]{4}{*}{ High } & Near & 1 & $\mathrm{~T} 1$ & $0.88 \pm 0.83$ \\
\hline & & 1.5 & $\mathrm{~T} 2$ & $0.88 \pm 0.64$ \\
\hline & Far & 1 & T3 & $0.38 \pm 0.74$ \\
\hline & & 1.5 & $\mathrm{~T} 4$ & $0.63 \pm 1.41$ \\
\hline \multirow[t]{4}{*}{ Low } & Near & 1 & T5 & $1.13 \pm 0.99$ \\
\hline & & 1.5 & T6 & $1.38 \pm 1.60$ \\
\hline & Far & 1 & $\mathrm{~T} 7$ & $1.50 \pm 2.07$ \\
\hline & & 1.5 & T8 & $0.50 \pm 1.07$ \\
\hline
\end{tabular}

Abbreviations: SD, standard deviation; T1, treatment one; T2, treatment two; T3, treatment three; T4, treatment four; T5, treatment five; T6, treatment six; T7, treatment seven; T8, treatment eight.

${ }^{\mathrm{a}}$ High $=0.71 \mathrm{~m}$ and low $=0 \mathrm{~m}$.

b Near $=1.60 \mathrm{~m}$ and $\mathrm{far}=10 \mathrm{~m}$. at the high level $(0.71 \mathrm{~m})$ reduced the occurrences of pinned back ears behavior. These effects occurred in just one comparison each (see comparisons between treatments five and six; treatments two and six, respectively; Fig. 3B).

\section{Discussion}

We demonstrate here that both the distance and the height positioning of feeding troughs, besides their proportion per individual, affect agonistic behaviors in horses while they are feeding in a group. Furthermore, we found that a better social stability can influence such effects. The far distance and high positioning of troughs reduce the frequency of kicks regardless of the social stability (Fig. 2). In contrast, the effects of the height and proportion of troughs on the pinned back ears vary according to such stability. Only a far distance between troughs reduces pinned back ears behavior independently of the social homeostasis (Figs. 3A and 3B). In this context, as pinned back ears is significantly the most frequent agonistic behavior between individuals (section 3.1), we recommend a far distance between troughs (of at least $10 \mathrm{~m}$ ) to decrease such behavior in horses, regardless of their social stability, to improve their welfare conditions.

According to Van Dierendonck et al [17], the competition between horses for resources increases proportionally with the restriction of the coexistence area of the individuals. Thus, the fact that one of the direct agonistic behaviors such as the kick was reduced by the imposition of the far distance between feeding troughs (Fig. 2) indicates

Table 3

There was no difference in behavioral frequencies of bite between treatments, independent of the tested phase (generalized linear models, $P>.05 ; \mathrm{n}=8)$.

\begin{tabular}{lllll}
\hline Bite & & & \\
\hline Factors & & & Treatments & Mean \pm SD \\
\hline Height $^{\mathrm{a}}$ & Distance $^{\mathrm{b}}$ & Proportion & & \\
\hline High & Near & 1 & T1 & $1.25 \pm 1.58$ \\
& & 1.5 & T2 & $1.50 \pm 2.78$ \\
& Far & 1 & T3 & $0.75 \pm 1.04$ \\
Low & \multirow{2}{*}{ Near } & 1.5 & T4 & $0.38 \pm 0.74$ \\
& & 1.5 & T5 & $1.00 \pm 1.41$ \\
& Far & 1 & T6 & $0.88 \pm 1.13$ \\
\end{tabular}

Abbreviations: SD, standard deviation; T1, treatment one; T2, treatment two; T3, treatment three; T4, treatment four; T5, treatment five; T6, treatment six; T7, treatment seven.

There was no occurrence of bite in treatment eight. Thus, data from this treatment were removed from analysis.

${ }^{\mathrm{a}}$ High $=0.71 \mathrm{~m}$ and low $=0 \mathrm{~m}$.

b Near $=1.60 \mathrm{~m}$ and $\mathrm{far}=10 \mathrm{~m}$. 
KICKING

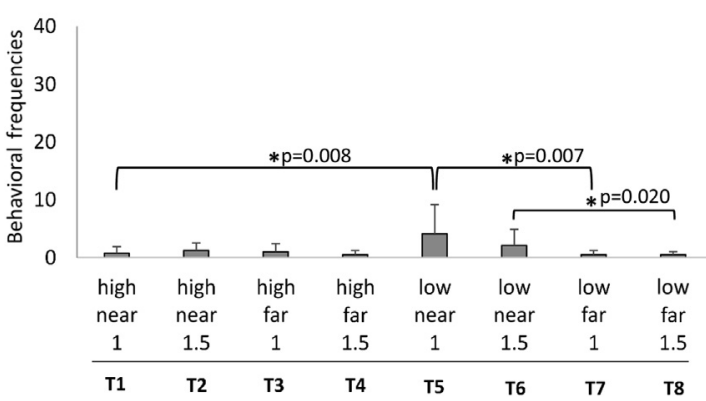

Fig. 2. Effects of distance and height positioning of the troughs on behavioral frequencies of kick $(\mathrm{n}=8)$. *Indicates significant differences (generalized linear models, $P<.05$ ) between two treatments in which only one of the factors (distance, height, or proportion) varied in level. The other significant differences between two treatments were disregarded. Data are presented as mean \pm SD. Abbreviations: SD, standard deviation; T1, treatment one; T2, treatment two; $\mathrm{T} 3$, treatment three; $\mathrm{T} 4$, treatment four; $\mathrm{T} 5$, treatment five; $\mathrm{T} 6$, treatment six; $\mathrm{T} 7$, treatment seven; $\mathrm{T} 8$, treatment eight.

that the restriction of feeding space may cause a consequent invasion of the "flight zone" between animals. Moreover, this invasion is prevented when the distance between troughs is greater. In this context, we demonstrated that when the troughs are more distant from each other, there may be a decrease in competition for food, and the individual "flight areas" are maintained between the horses. As a consequence, there is a decrease in the frequency of direct and more agonistic interactions, such as kicks, which may prevent injury to horses.

Moreover, troughs arranged in a high level above the ground also caused a reduction of kicks between individuals (Fig. 2). A possible explanation for this result is that troughs positioned at a higher level above the ground should allow a wider field of vision for the animals which probably would make them less vulnerable and also less exposed while feeding. This situation may enable horses to rapidly inhibit the approach of other group members, probably through a signaling of a threat indicated by the pinned back ears behavior, without the need to invest in direct agonistic interactions. However, because a far distance between the troughs reduced the occurrence of kicks in two comparisons (Fig. 2), with a high positioning of such troughs reducing this agonistic behavior only in one comparison (Fig. 2), the distance between the troughs should be more effective than their height positioning in reducing such behavior.

Furthermore, the effects on kick behavior were independent of the social homeostasis. In contrast, the effects of height and proportion of troughs on the agonistic pinned back ears behavior depended on such stability. Ransom and Cade [18] and Van Dierendonck et al [17] showed that pinned back ears behavior, when in isolation (without direct physical interactions), is a sign of social stability and it is classified as a threat which normally inhibits the submissive animals [19]. The submission demonstration, such as avoiding a conflict [20], is a much more expressive way of dominant behavior than the aggression itself [21]. According to Van Dierendonck et al [17], direct agonistic behaviors such as kicking do not significantly indicate the social position of the animal in the group. Thus, kicking

\section{A PINNED BACK EAR - primary phase (test 1)}
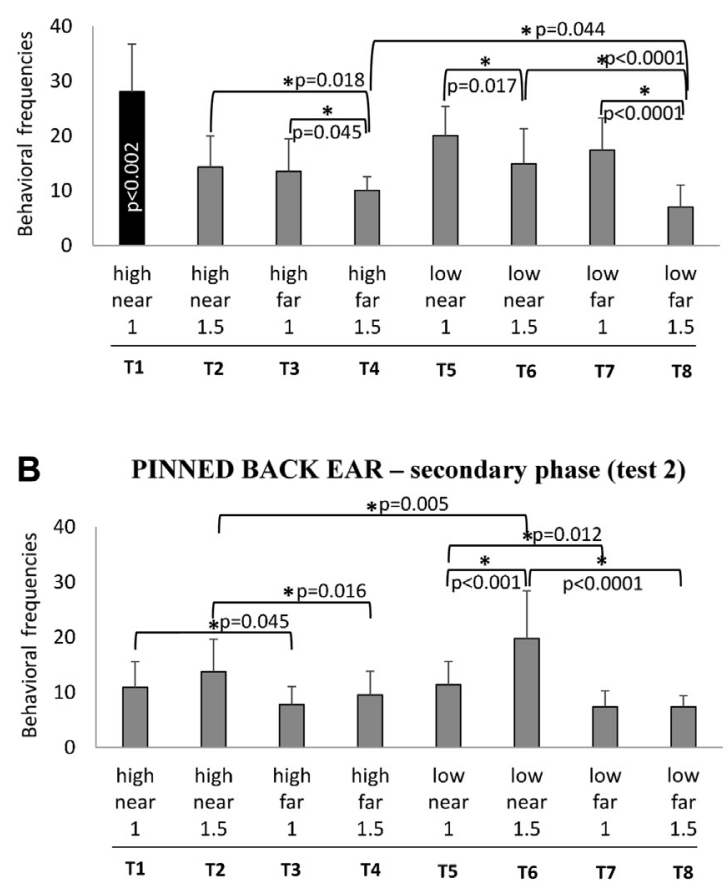

Fig. 3. Effects of distance, height positioning, and proportion of troughs on behavioral frequencies of pinned back ear in the primary (A) and secondary (B) phases of experimentation (tests 1 and 2, respectively; $n=8$ ). The black bar indicates that treatment one was significantly the highest frequency of pinned back ear than in all other treatments, and *indicates significant differences between two treatments in which only one of the factors (distance, height, or proportion) varied in level (generalized linear models, $P<$ .05). The other significant differences between two treatments were disregarded. Data are presented as mean \pm SD. Abbreviations: SD, standard deviation; T1, treatment one; T2, treatment two; T3, treatment three; T4, treatment four; $\mathrm{T} 5$, treatment five; $\mathrm{T} 6$, treatment six; $\mathrm{T} 7$, treatment seven; T8, treatment eight.

behavior may not depend on the social homeostasis, whereas the occurrence of pinned back ears behavior should be more influenced by such stability.

According to Heitor et al [15,22], the social stability is important to reduce agonistic behaviors and maintain affiliative relationships, leading to the homeostasis and security of the herd, as stated by Lindberg [23]. Thus, in our study, we expected that, at least, some effects would be different between the tested phases. Initially (primary phase; test 1 ), the interaction between the near distance, the lower proportion, and the arrangement of troughs at a high level reflected the highest frequency of pinned back ears behavior (Fig. 3A). Moreover, a greater proportion of troughs per individual, as well as the far distance between them, and a low positioning reduced the occurrences of such behavior independently (Fig. 3A). However, after a probable better social homeostasis in the secondary phase (test 2 ), only the effect of the distance between troughs on pinned back ears remained consistent, besides being intensified (compare Figs. 3A and 3B). The effects of the other factors on such behavior were opposite (compare Figs. 3A and 3B). Thus, only the distance between troughs affects the pinned back ears behavior regardless of the social stability. 
According to Ransom and Cade [18], the most agonistic behaviors among horses do not involve direct physical contact. Submissive horses are usually skilled in avoiding conflicts [24], probably responding to signals of threat from the dominants. Heitor et al $[15,22]$ showed a great percentage of the agonistic signaling pinned back ears behavior. In fact, here, we showed that such behavior was the most frequent agonistic interaction among individuals (section 3.1), regardless of the phase evaluated (test 1 or test 2). Considering that behavioral change must be one consequence of the restriction of feeding space generated by the confinement of horses [25], the reduction of excessive occurrences of the agonistic behavior pinned back ears should be given relevance to ensure better welfare conditions for horses.

The agonistic behaviors of rush and bite were not significantly affected by height positioning, distance, or proportion of troughs, regardless of the social stability (Tables 2 and 3). This fact can be explained by the low occurrence of these behaviors, in addition to a high variability in their frequencies (see the averages and standard deviations in Tables 2 and 3). Thus, our findings confirm that direct agonistic interactions, such as rush and bite, are less frequent among horses than agonistic signaling. Note that direct agonistic interaction of kicking, although affected by some tested factors, was also significantly less frequent than the agonistic signaling pinned back ears behavior (compare behavioral frequencies between Figs. 2 and 3 and see section 3.1).

\section{Conclusions}

We conclude that both the distance between feeding troughs and their height positioning, besides their proportion per individual, affect agonistic behaviors in horses while they are grouped and feeding in confinement. The effects on kick behavior are independent of the social stability, but the effects on pinned back ears behavior may be dependent of such homeostasis. Only a far distance between the troughs reduces the occurrences of pinned back ears irrespective of the social stability, and this effect is stronger when such stability is more clearly established. Considering that agonistic interactions may result in increased stress, lower growth, and even lower survival and that pinned back ears behavior is the most frequent one, it is relevant to minimize such interactions. Thus, our study unravels this issue in a practical and simple way: using widely spaced troughs, which may reduce this agonistic behavior regardless of the social stability.

\section{Acknowledgments}

The authors thank Iuri Emmanuel P. Ferreira for his help with the experimental design and Altamiro Rosam and Felipe Prosdocini for their great help with the data collection. This research was funded by the Foundation for Research Support of the State of São Paulo, Brazil (FAPESP) (process number: 2012/12192-9), which had no involvement with the study design; collection, analysis or interpretation of the data; in the writing of the report and about the decision to submit the article for publication. M.P.F.L.,
M.C.N., and J.N.P.P.F. conceptualized and designed the study. M.P.F.L. collected the data. C.M.M. and J.C.F.P. analyzed the data. C.M.M., M.P.F.L., J.C.F.P., and J.N.P.P.F. interpreted the results. C.M.M. wrote the article. All authors have approved the final article version.

The authors declare no competing financial interests.

\section{References}

[1] Enquist M, Leimar O. The evolution of fatal fighting. Anim Behav 1990;39:1-9.

[2] Beaugrand JP, Zayan R. An experimental-model of aggressive dominance in Xiphophorus helleri (Pisces, Poeciliidae). Behav Processes 1985; 10:1-52.

[3] Barreto RE, Carvalho GGA, Volapto GL. The aggressive behavior of Nile tilapia introduced into novel environments with variation in enrichment. Zoology 2011;114:53-7.

[4] Matthews LR, Ladewig J. Environmental requirements of pigs measured by behavioural functions. Anim Behav 1994;47:713-9.

[5] Warburton H, Mason G. Is out of sight out of mind? The effects of resource cues on motivation in mink, Mustela vison. Anim Behav 2003;65:755-62.

[6] Mason GJ, Cooper J, Clarebrough C. Frustrations of fur-farmed mink Nature 2011;410:35-6.

[7] Cozzi A, Sighieri C, Gazzano A, Nicol CJ, Baragli P. Post-conflict friendly reunion in a permanent group of horses (Equus caballus). Behav Processes 2010;85:185-90.

[8] Paranhos Da, Costa MJR. Ambiência na produção de bovinos de corte a pasto. Anais de Etologia 2000;18:26-42.

[9] Mills D, Nankervis K. Equine behaviour: principles and practicemechanisms of behavior: communication and social organization. 2nd ed. Lincoln: Wiley-blackwell; 2005.

[10] Meyer H. Alimentação de cavalos. 2nd ed. São Paulo: Varela; 1995.

[11] Merico M. Como construir as melhores baias para cavalos. In: O cavalo-características, manejo, alimentação e estudos complementares - adaptação: escola do cavalo, http://www.Escoladocavalo. Com.Br/2012/01/Como-Construir-As-Melhores-Baias-Para-Cavalos/; 2013. accessed July 26, 2013.

[12] Wheeler EF. Horse stable and riding arena design. Ames: Blackwell Publishing; 2006.

[13] National Research Council. Nutrient requirements of horses. 6th ed Washington: Washington National Academic Press; 2007.

[14] Budiansky S. The nature of horses: exploring equine evolution, intelligence and behavior. New York: Simon and Schuster; 1997.

[15] Heitor F, Oom MM, Vicente L. Social relationships in a herd of Sorraia horses. Part I. Correlates of social dominance and contexts of aggression. Behav Processes 2006a;73:170-7.

[16] Goodman LA. On simultaneous confidence intervals for multinomial proportions. Technometrics 1965;7:247-54.

[17] Van Dierendonck MC, Vries H, Schilder M. An analysis of dominance, its behavioural parameters and possible determinants in captivity. Neth J Zool 1995;3-4:362-85.

[18] Ransom JI, Cade BS. Quantifying equid behavior: a research ethogram for free-roaming feral horses. Reston: U.S. Geological Survey; 2009.

[19] McDonnell SM. The equid ethogram: a practical field guide to horse behavior. Lexington: Eclipse Press; 2003.

[20] Menezes AGC, Chiquitelli Neto M, Silvestre D, Pereira YS, Camerro LZ, Garoli TA, et al. Influência da quantidade de cochos na qualidade do bem-estar de equinos durante alimentação: indicadores comportamentais. In: XXIII Congresso Brasileiro de Zootecnia, Foz do Iguaçu/Pr. Zootecnia do futuro: produção animal sustentável, 1. Foz do Iguaçu: Abz. p. 1-3, http://Zootec.Org.Br/V2/; 2013. accessed July 15, 2013.

[21] Van Hooff JA, Wensing JA. Dominance and its behavioural measures in a captive wolf pack. In: Frank H, editor. Man and wolf. Dordrecht: Junk Publishers; 1987. p. 219-52.

[22] Heitor F, Oom MM, Vicente L. Social relationships in a herd of Sorraia horses. Part II. Factors affecting affiliative relationships and sexual behaviours. Behav Processes 2006b;73:231-9.

[23] Lindberg AC. Group life. In: Keeling LJ, Gonyou HW, editors. Social behaviour in farm animals. Wallington, UK: CAB International Publishers; 2001. p. 37-58.

[24] Fraser AF. The behaviour of the horse. New York: Cab International; 1992.

[25] Fraser AF. The behaviour of the horse - developmental and social behaviour. 2nd ed. Oxfordshire: Cabi publishing; 2010. 

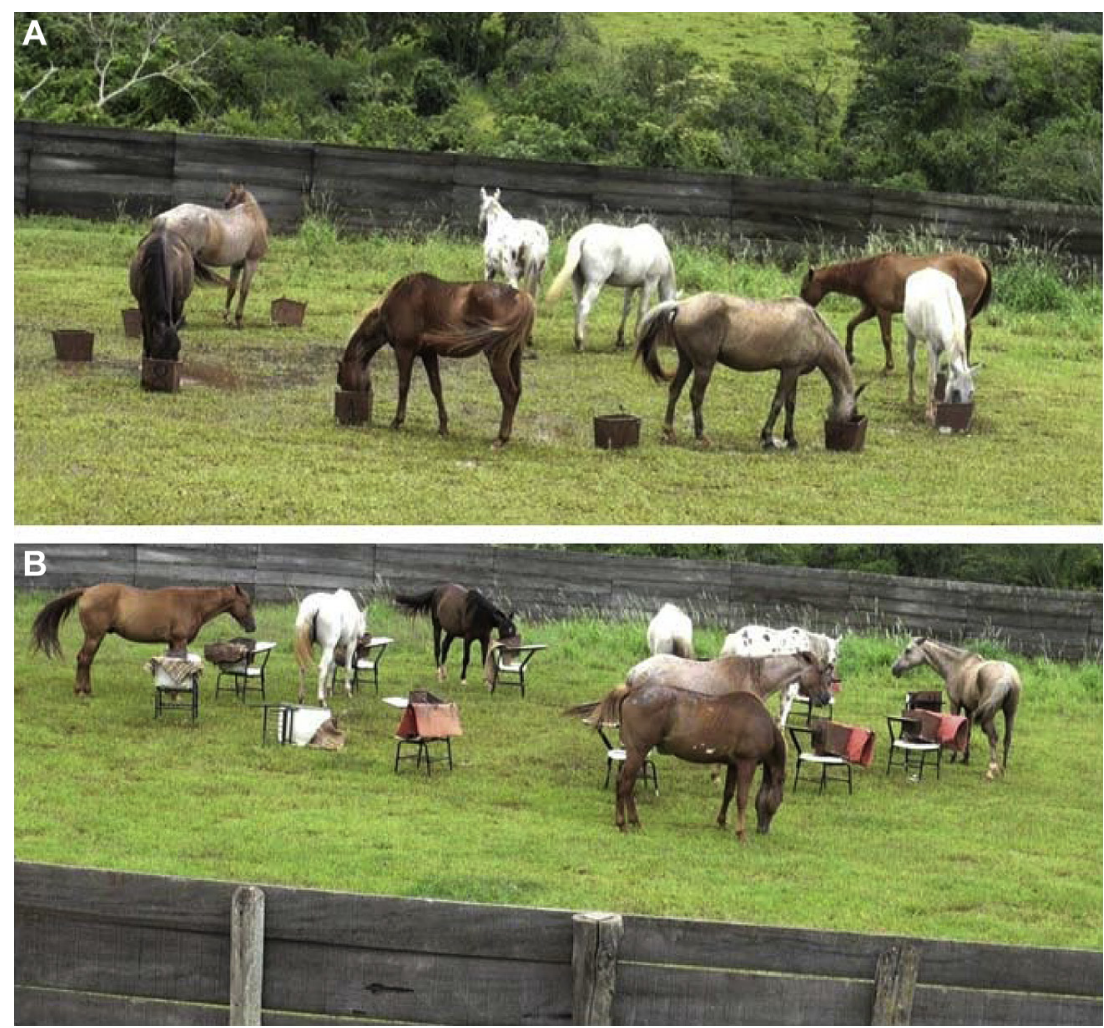

Fig. S1. Horses feeding in troughs with height positioning of $0 \mathrm{~m}$, at ground level (A), and at average height of horse breast (0.71 $\mathrm{m}$ from the upper edge of the trough to the ground), in a high level (B). 